\title{
Investigating the Epidemiological Prevalence of Diabetes in Afghanistan from 2015 to 2019
}

\author{
Research Article
}

\section{Shokreya Ehsani', Pouriya Darabiyan ${ }^{2}$, Kourosh Zarea ${ }^{3}$, Saeed Ghanbari ${ }^{4}$, Aseya Temori ${ }^{*}$}

\begin{abstract}
1.Medical Science Research Center, Ghalib University, Kabul, Afghanistan.
2. Student Research Committee, Ahvaz Jundishapur University of Medical Sciences, Ahvaz, Iran.

3. Associate Professor, Nursing Care Research Center in Chronic Diseases, Nursing Department, School of Nursing \& Midwifery, Ahvaz Jundishapur University of Medical Sciences, Ahvaz, Iran.

4. Assistant professor, Department of Biostatistics and Epidemiology, School of Public Health, Ahvaz Jundishapur University of Medical Sciences, Ahvaz, Iran.

5.Medical Science Research Center, Ghalib University, Kabul, Afghanistan.
\end{abstract}

\begin{abstract}
Introduction: Diabetes is one of the most common metabolic disorders and is one of the top 10 leading causes of death in adults. Therefore, this study was conducted to investigate the epidemiological prevalence of diabetes in Afghanistan between 2015 and 2019. Methods: This descriptive cross-sectional study was performed using the information of diabetics registered in the system related to the Ministry of Health of Afghanistan from 2015 to 2019. Eventually, people's information, including age, gender, and place of residence, was entered into STATA software version 12 and analyzed using descriptive statistics tests. Results: The study, which was performed on 49,332 people with diabetes in 34 provinces and 8 regions of Afghanistan, found that most of the female studied were 55.2\% $(27,231)$ female and had the highest and lowest prevalence in the region. The order is related to South East and South. The average prevalence of diabetes per 10,000 people is about 62.13. Conclusions: The prevalence of diabetes in Afghanistan over a five-year period in men and women is on the rise, requiring more attention from relevant authorities to improve public health and prevent, control and treat chronic diseases such as diabetes.
\end{abstract}

Key Words: Diabetes, Prevalence, Afghanistan, Epidemiology.

\section{Introduction}

Diabetes is one of the most common metabolic disorders, yet serious illness and long-term, which has a major impact on the welfare of individuals, families, life and human societies is such that the disease among the 10 leading causes of death among adults is $(1,2)$. Studies by the World Health Organization show that mortality from diabetes will double between 2005 and 2030 (3). In fact, diabetes is defined as a group of metabolic disorders characterized by insulin deficiency, insulin resistance, or a combination of both(4). Complications of diabetes include the risk of heart disease, kidney disease, blindness and amputation(5). The disease is divided into three main types, including type 1 diabetes (T1D), type 2 diabetes (T2D), and gestational diabetes (GDM)(1). Meanwhile, type 2 diabetes, which accounts for about $90 \%$ of all types of

\section{* Corresponding Author:}

\section{Aseya Temori}

Medical Science Research Center,

Ghalib University,

Kabul,

Afghanistan

Email Id: aseya.temori@ghalib.edu diabetes, is on the rise, which can be caused by increased urbanization, lifestyle changes, and increased obesity(6). Over the past decades, many studies have been conducted in different populations and regions of the world to determine the prevalence of this disease(7) According to research, the global prevalence of diabetes is estimated to be $10.9 \%$ by $2045(1)$. Approximately $80 \%$ of people with diabetes live in low-income or middle-income countries, and extensive research is important in these areas(8). On the other hand, due to the years of war and conflict in Afghanistan, few studies have been conducted to estimate the prevalence of diabetes in this country(9). The results of some studies in the country on the prevalence of diabetes in the age group of 20 to 79 years in 2010 were estimated at 8.6\%, while by 2030 it is expected to reach 9.9\%(10). Also in two studies conducted by Saeed in 2015, the prevalence of diabetes in Kandahar and Herat was reported to be $22.4 \%$ and $9.9 \%$, respectively $(9,11)$. Given the importance of diabetes and its increase, especially in less developed countries (South Asia) (12) and the lack of a comprehensive and epidemiological study in Afghanistan, and the importance of such studies, this study aims to investigate the epidemiological prevalence of diabetes in Afghanistan. It was done from 2015 to 2019. 
Shokreya Ehsani et.al., Investigating the Epidemiological Prevalence of Diabetes in Afghanistan from 2015 to 2019

\section{Methods}

This descriptive -sectional study was performed using the information of diabetics registered in the system related to the Ministry of Health of Afghanistan from 2015 to 2019.

The Ministry of Public Health (MoPH) in collaboration with the USAID funded Health Sector Resiliency (HSR) project developed and launched the first version of the MoPH data warehouse using the web-based health District Health Information Software (DHIS-2) on August 29th, 2017. The MoPH Data Warehouse will be an online, central repository for all health data where MoPH, government officials, and program implementers can access and monitor program implementation and service delivery in the different parts of the country, and at multiple-levels which include the central, regional, provincial and district level. Also, through the data warehouse, the MoPH will provide easier access to information to facilitate evidence based decision making. For this study we analyzed data from Essential health package services (EPHS)(13).

In order to gather information, while taking into account the ethical considerations of the Ethics Committee of Ghalib University, as well as the Ministry of Health of Afghanistan and obtaining the relevant licenses, the data recorded from different parts of Afghanistan were obtained. For 5 years of study, the data of 49,332 people were used in 8 districts and 34 provinces. In this study, people were divided into two age groups of more than 5 years and less than 5 years. Eventually, people's information, including age, gender, and place of residence, was entered into STATA software version 12 and analyzed using descriptive statistics tests.

\section{Results}

The study, which looked at 49,332 people with diabetes in 34 provinces and 8 regions of Afghanistan, looked at data from the province and the region, including Central East, Central West, East, North, North East, South, South East and West., Age (less than 5 years or more than 5 years) and gender were analyzed. In this study, $55.2 \%$ (27,231 people) were female and the rest were male, with age, $96.7 \%$ of people over 5 years old. The gender and age of the subjects were shown in Figure 1 by year. According to the Figure, the prevalence of sex-based diabetes in both women and Male has increased over the past five years, with the exception of 2017, which has been declining since 2016. On the other hand, the number of people with diabetes with an age of more than 5 years and less than 5 years has increased, except in 2016, when the number of people under 5 years of age decreased compared to 2015. Also, the number of people with diabetes over the age of 5 in 2017 has decreased slightly compared to 2016. The year 2019 also had the highest prevalence of diabetes $(24.2 \%)$ among people based on gender and age compared to previous years.

\section{Figure 1. Gender and age of the subjects studied by year}

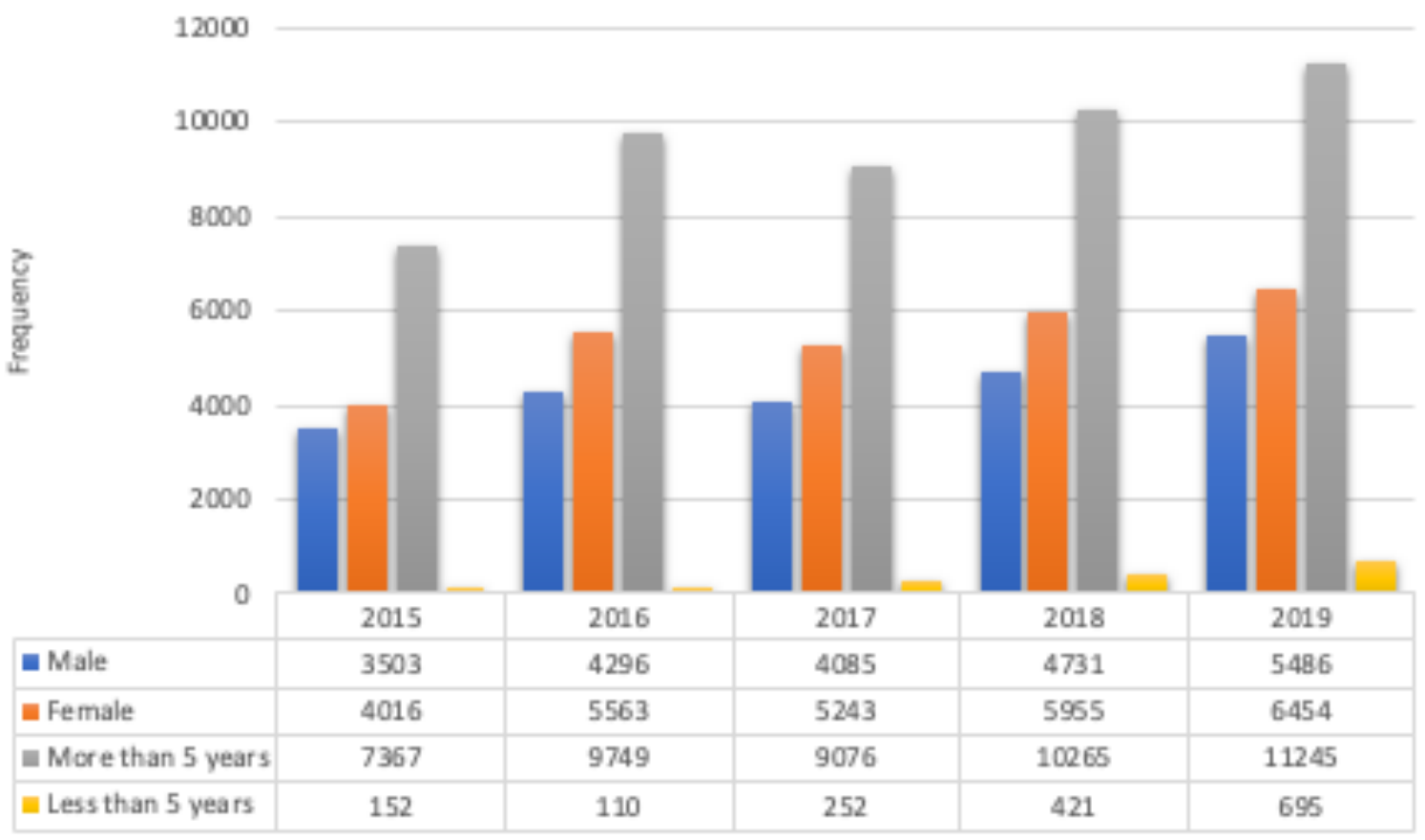

The gender and age of the subjects were shown separately in Figure 2. Accordingly, the highest and lowest number of people surveyed lived in Central East (25.6\%) and Central West (5.1\%), respectively. Also regions Central East(female: $14.9 \%$ male: $10.7 \%$ ), East(female: $10.3 \%$ male: $8.5 \%$ ) and West(female: $9.3 \%$ male: $8.2 \%$ ) had the most male and female subjects, respectively. On the other hand, Central West(female: $3.0 \%$ male: $2.1 \%$ ), South(female: $4.4 \%$ male: $4.1 \%$ ) and South East(female: $4.4 \%$ male: $4.5 \%$ ) had the lowest number of male and female subjects, respectively. In terms of age, Central East( $>5$ year: $25.4 \%<5$ year: $31.5 \%$ ) and Central West $(>5$ year: $5.3 \%<5$ year: $0.7 \%$ ), respectively, had the highest and lowest number of people over 5 years and less than 5 years. 
Figure 2. Gender and age of the subjects studied by region

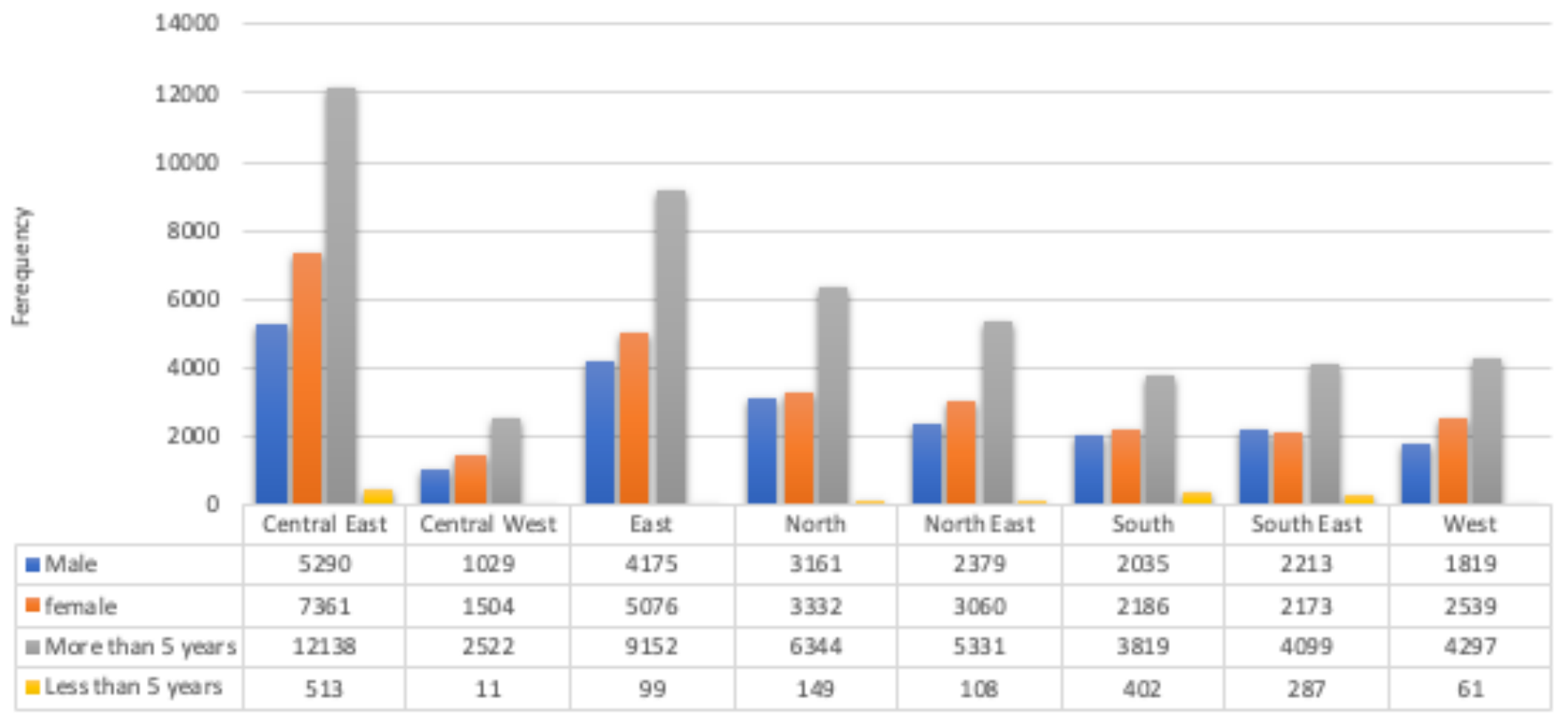

The gender and age of the subjects studied by the province are shown in Figure 3 and Figure 4. Accordingly, the highest and lowest number of study subjects were in Kabul (24.1\%) and (approximately 0\%) Nooristan provinces, respectively. Also provinces Kabul(female: $13.9 \%$ male: $10.2 \%$ ), Balkh(female: $4.6 \%$ male: $4 \%$ ) and Herat(female: $3.93 \%$ male: $2.8 \%$ ) had the most male and female subjects, respectively. On the other hand, the provinces of Nooristan(female: $0.0 \%$ male: $0.0 \%$ ), Panjsher(female: $0.0 \%$ male: $0 / 0 \%$ ) and Badghis(female: $0.2 \%$ male: $0.1 \%$ ) had the lowest number of male and female subjects, respectively. In terms of age, Kabul( $>5$ year: $\% 23.1<5$ year: $30.7 \%$ ) and Nooristan $>5$ year: $0.0 \%<5$ year: $0.0 \%$ ) provinces had the highest and lowest number of people over 5 years and less than 5 years, respectively.

Figure 3. Gender and age of the subjects studied by province

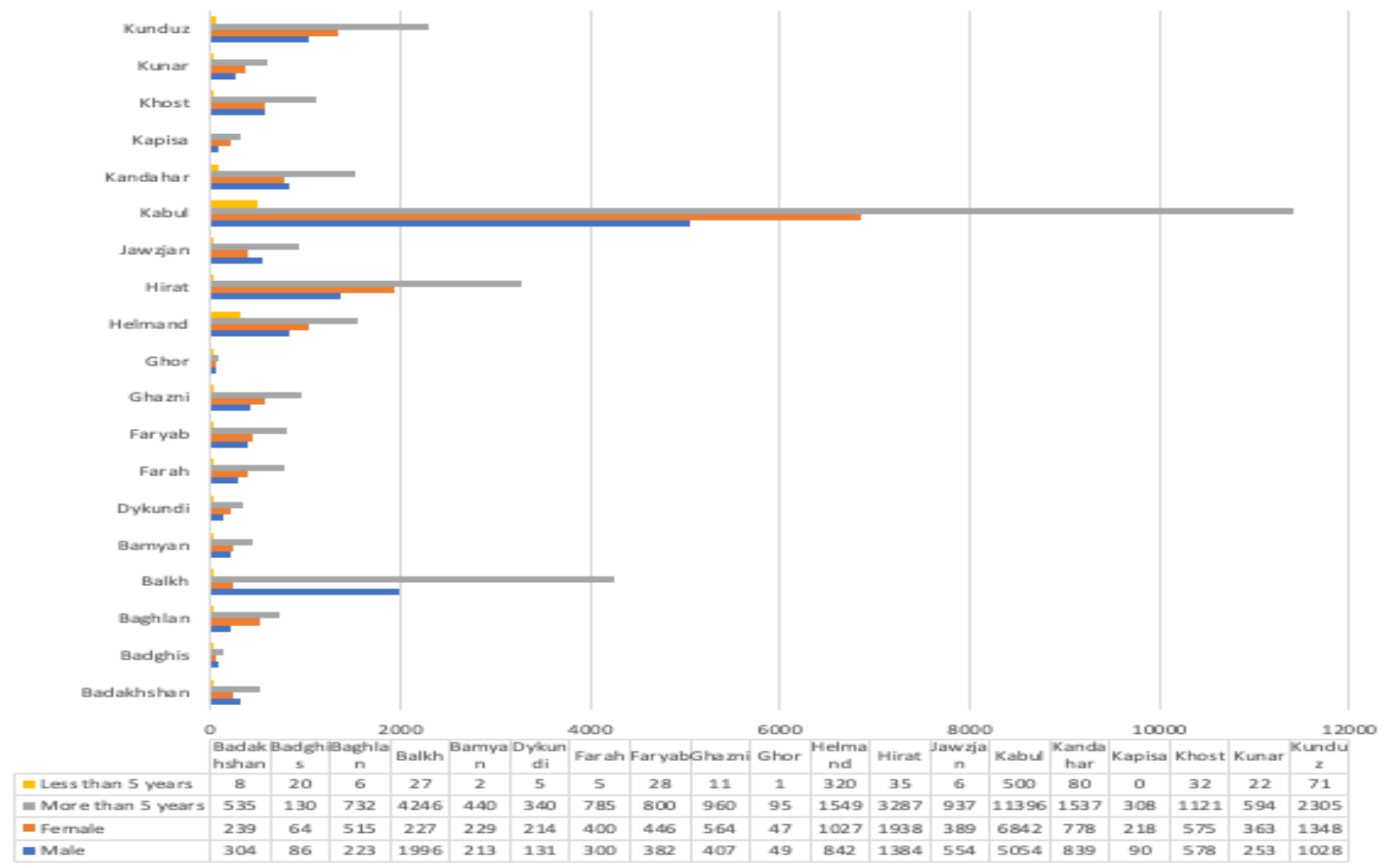




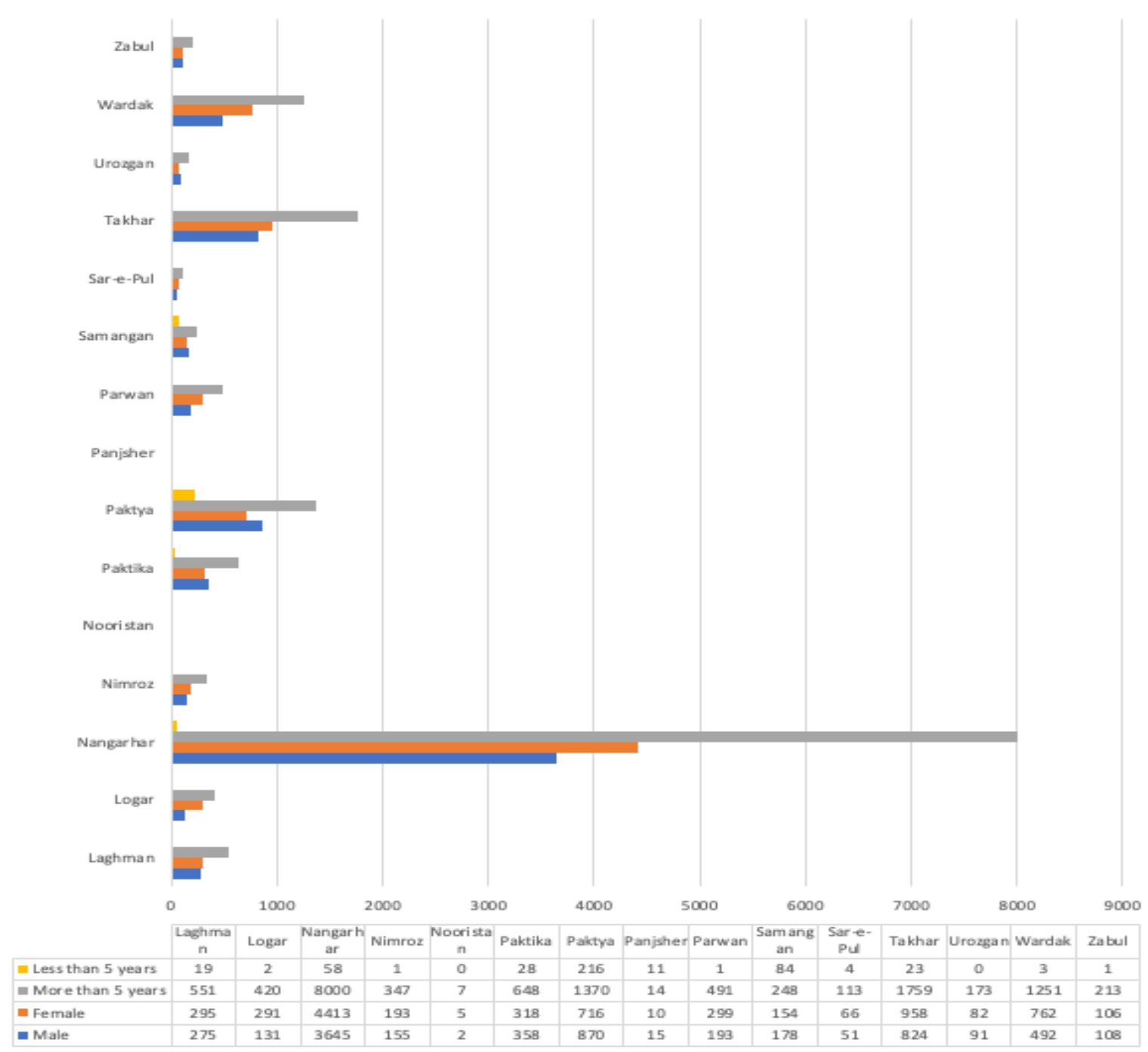

Table 1 shows the overall prevalence of diabetes in the eight regions of Afghanistan at 10,000. Accordingly, the highest prevalence is in the South East, East and Central East, respectively. It also has the lowest prevalence in the South, West and Central West regions. According to the findings of this table, on average, for every 10,000 people, there are about 62.13 diabetics.

Table 1. The overall prevalence of diabetes in Afghanistan's eight regions averages 10,000

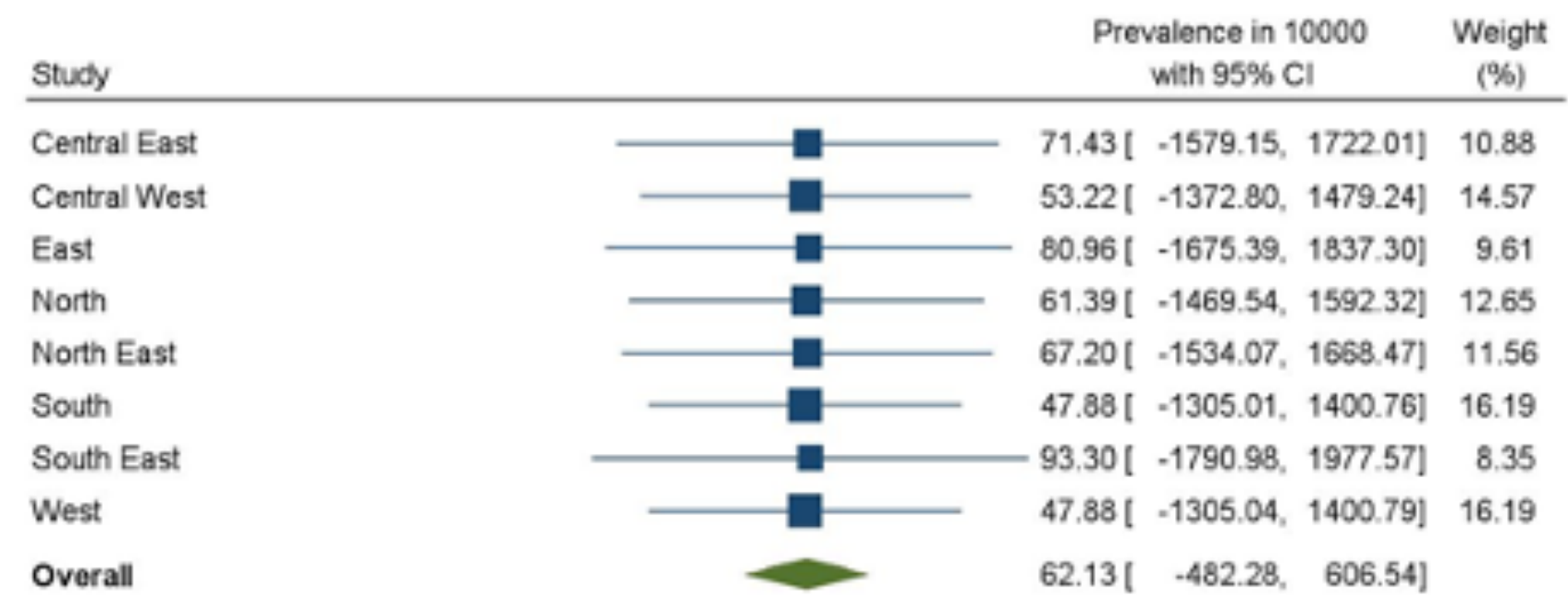




\section{Discussion}

The aim of this study was to evaluate the epidemiology of diabetes in Afghanistan using data registered in the Ministry of Health of this country on 49,332 people. The study found that most people with diabetes were women $(55.2 \%)$. In the Saeed study, the results showed that diabetes was more common in women than in men (8), and the results of two other Saeed studies in Afghanistan showed that diabetes was more common in women than men, all They are consistent with the results of the present study $(11,9)$. At the same time, in another study conducted in Kabul for the prevalence of diabetes mellitus and the risk factors associated with it in the citizens of this city, the percentage of this disease was reported in men more than women (14) which is not consistent with the results of the present study. Regarding the causes of high diabetes in females compared to males, it can be stated that factors such as: hormonal and genetic differences (15) even differences in fat storage in both sexes (in women more in the buttocks and thighs and in men more in the abdomen ) Have a significant impact on these statistics (5). The results of this study also showed that the number of people with diabetes over 5 years of age is significantly higher than people under 5 years of age, which indicates the relationship between increasing age and the prevalence of diabetes (16).

Regarding the prevalence and prevalence of diabetes in the study areas and provinces over a period of 5 years, the highest prevalence was in the South East region, with Saeed's study showing high prevalence of diabetes in Kandahar (southern Afghanistan) compared to other cities. Afghanistan was another (11), aligned. The overall findings of this study show an increase in the prevalence of diabetes in Afghan society over the past five years, which is consistent with the predictions made in the study of Shaw et al. Given that this study was conducted over a 5-year period, the results can be more confidently distributed to the entire community.

\section{Conclusion}

Given that the prevalence of diabetes in Afghanistan is increasing, although in some years compared to the previous year there has been a slight decline, but it should be noted that the number of patients in 2019 compared to 2015 has grown significantly. It requires more attention from the relevant authorities to educating and informing people about diabetes and the right lifestyle, as well as raising public health. Attention to the prevention, control and treatment of these patients should also be a priority for the Afghanistan Ministry of Health.

\section{Acknowledgments}

The authors consider it necessary to thank the General Directorate of Supervision and the Health Information System of the Ministry of Public Health of Afghanistan for providing this information to them by granting them access to the MoPH system. This study is the result of a research project approved by the Ghalib
University of Kabul with the Approval code AF.GU.REC.1399.001.

\section{Conflict of interest}

Authors have no conflict of interest.

\section{References}

1. Saeedi P, Petersohn I, Salpea P, et al. Global and regional diabetes prevalence estimates for 2019 and projections for 2030 and 2045: Results from the International Diabetes Federation Diabetes Atlas, 9 th edition. Diabetes Res Clin Pract. $2019 ; 157: 107843$. doi:10.1016/ j.diabres.2019.107843

2. Guariguata L, Whiting DR, Hambleton I, Beagley J, Linnenkamp U, Shaw JE. Global estimates of diabetes prevalence for 2013 and projections for 2035 . Diabetes Res Clin Pract. $2014 ; 103(2): 137-149$. doi:10.1016/ j.diabres.2013.11.002

3. Viskum, Elizabeth Sejr, and Michael Lynge Pedersen. "Prevalence of diagnosed diabetes and quality of care among Greenlanders and nonGreenlanders in Greenland." Diabetes research and clinical practice 121 (2016): 91-98. doi: 10.1016/ j.diabres.2016.09.006

4. Anne B, Michael C, Parveen K, editors. Essentials of Kumar \& Clark's clinical medicine. 5th ed., Edinburgh: Saunders; 2011. p. 667-701. Chapter 15. Diabetes mellitus and other disorders of metabolism.

5. Nayak, B. Shivananda, et al. "The association of age, gender, ethnicity, family history, obesity and hypertension with type 2 diabetes mellitus in Trinidad." Diabetes \& Metabolic Syndrome: Clinical Research \& Reviews 8.2 (2014): 91-95.doi: 10.1016/j.dsx.2014.04.018

6. DIAMOND Project Group. Incidence and trends of childhood type 1 diabetes worldwide 1990-1999. Diabet Med J Br Diabet Assoc. 2006;23(8):857-66

7. Liatis S, Dafoulas GE, Kani C, et al. The prevalence and treatment patterns of diabetes in the Greek population based on real-world data from the nation-wide prescription database. Diabetes Res Clin Pract. 2016;118:162-167. doi:10.1016/ j.diabres.2016.06.018

8. Mir Islam S K. Prevalence and Predictors of Diabetes Mellitus in Jalalabad City, Afghanistan-2013. IJDO. 2014; 6 (1) :1-8

9. Islam Saeed, Khwaja Mir. "Diabetes Mellitus Among Adults in Herat, Afghanistan: A CrossSectional Study." Central Asian journal of global health vol. 6,1 271. 25 Aug. 2017. doi:10.5195/ cajgh.2017.271

10. Shaw JE, Sicree RA, Zimmet PZ. Global estimates of the prevalence of diabetes for 2010 and 2030. Diabetes Res Clin Pract. 2010;87(1):4-14. doi:10.1016/j.diabres.2009.10.007

11. Saeed, Khwaja Mir Islam. "Prevalence of Diabetes and its Risk Factors in Urban Setting of Kandahar 
City, Afghanistan-2015." IOSR Journal of Pharmacy 6.11 (2016): 53-60

12. Gallagher J. Diabetes warning for people of Asian, African and Caribbean descent [Internet]. BBC News United Kingdom; 2013, available at http:// www.bbc.co.uk/news/health-19545697 [updated 2012 September; cited 12.10.12].

13. From https://moph-dw.gov.af

14. Saeed, K.M.I., Asghar, R.J., Sahak, M.N. et al. Prevalence and risk factors associated with diabetes mellitus among Kabul citizens-Afghanistan, 2012.
Int J Diabetes Dev Ctries 35, 297-303 (2015). doi.org/10.1007/s13410-014-0270-3.

15. Izadi N, Rahimi M, Rezvanmadani F, Shetabi H, Darbandi M. A Survey on Epidemiology of Type II Diabetes in Patients Referring to the Diabetes Clinic in Kermanshah Province du ring 2013-14: A Short Report . JRUMS. 2017; 16 (1) :83-90. [Persian]

16. International Diabetes Federation. IDF Diabetes Atlas, 8th ed. Brussels, Belgium: International Diabetes Federation; 2017. 